\title{
Article \\ Electrochemical Detection of Sarcosine and Supercapacitor Based on a New Ni-Metal Organic Framework Electrode Material
}

\author{
Shaomin Lin ${ }^{1}$, Yi Wang ${ }^{2}$, Chenyang Zhang ${ }^{1} \mathbb{D}$, Yunying Wu ${ }^{1,3}$, Bodong Zhang ${ }^{1}$, Chunjuan Zhou ${ }^{1}$ \\ and Huan Yang ${ }^{1, *(D)}$
}

1 The School of Material Science and Engineering, Hanshan Normal University, Chaozhou 521041, China; lsm678@hstc.edu.cn (S.L.); 2598@hstc.edu.cn (C.Z.); yunyingwu@hotmail.com (Y.W.); 2523@hstc.edu.cn (B.Z.); 2243@hstc.edu.cn (C.Z.)

2 College of Chemistry and Material Engineering, Guiyang University, Guiyang 550005, China; wy742011@hotmail.com

3 Guangdong Chaoshan Institute of Higher Education and Technology, Chaozhou 521041, China

* Correspondence: yanghuan@hstc.edu.cn

Citation: Lin, S.; Wang, Y.; Zhang, C.; Wu, Y.; Zhang, B.; Zhou, C.; Yang, H. Electrochemical Detection of Sarcosine and Supercapacitor Based on a New Ni-Metal Organic Framework Electrode Material. Crystals 2021, 11, 1036. https:/ / doi.org/10.3390/cryst11091036

Academic Editor: Dmitry Medvedev

Received: 14 July 2021

Accepted: 25 August 2021

Published: 28 August 2021

Publisher's Note: MDPI stays neutral with regard to jurisdictional claims in published maps and institutional affiliations.

Copyright: (c) 2021 by the authors. Licensee MDPI, Basel, Switzerland. This article is an open access article distributed under the terms and conditions of the Creative Commons Attribution (CC BY) license (https:// creativecommons.org/licenses/by/ $4.0 /)$.

\begin{abstract}
A new Ni metal organic framework based on 2,2'-Biphenyldicarboxylic, 4,4'- bipyridine as linker is prepared by hydrothermal reaction and directly used as an electrode material for supercapacitor and the detection of sarcosine. $\left[\mathrm{Ni}_{3}(\mathrm{BIPY})_{3}(\mathrm{BPDA})_{2}(\mathrm{HCOO})_{2}\left(\mathrm{H}_{2} \mathrm{O}\right)_{2}\right]_{\mathrm{n}}(\mathbf{N i}-\mathbf{1}$; $\mathrm{BIPY}=4,4^{\prime}$-bipyridine; $\mathrm{BPDA}=2,2^{\prime}$-Biphenyldicarboxylate) displays the specific capacitance of the Ni-1 are $667 \mathrm{~F} /$ gat $1 \mathrm{~A} / \mathrm{g}$ and retention is $82 \%$ of initial capacitance at $1 \mathrm{~A} / \mathrm{g}$. The excellent electrochemical property is ascribed to the intrinsic nature of Ni-1. Furthermore, the sarcosine sensing performance of the Ni-1 electrode is evaluated in $0.1 \mathrm{M}$ of $\mathrm{NaOH}$ solution and the electrode showed a wider range of linear response $1 \times 10^{-4} \mathrm{M}$ to $1 \times 10^{-3} \mathrm{M}$. Thus, the results show that the Ni-1 is a potential candidate for not only sensing of sarcosine but also supercapacitor application.
\end{abstract}

Keywords: electrochemical sensing; sarcosine; supercapacitor; Ni metal organic framework

\section{Introduction}

Potential threatening energy crisis and environmental pollution force scientists and engineers to develop clean and very efficient energy storage technologies to overcome these issues. Supercapacitors are among such novel energy solutions because they demonstrate high-power density, long-termstability, and fast charging and discharging when needed [1-6]. Pseudocapacitance is stored by the rapid Faraday redox reactions occurring on the active material surfaces. Pseudocapacitive materials have higher specific capacitances than carbon materials (EDLCs). For the purposes, MOFs have been demonstrated to be useful for electrochemical energy storage and are considered as the most promising electrode material candidatefor SCs due to their high surface area, tunable pore size, controllable pore structure, and special structures with potentialpseudo-capacitive redox centers [7-10].

Panprostate cancer (PCa), the most common malignant tumor diagnosed in males, if diagnosed early, could be successfully treated. Early diagnosis of PCA also significantly reduced the mortality rate [8]. Sarcosine, is considered as a differential metabolite, since sarcosine is increased during PCa progression to metastasis sarcosine and can be detected non-invasively in urine. Recently, many papers have reported sarcosine sensing [11-15]. Sarcosine detection techniques include high-performance liquid chromatography-mass spectrometry (HPLC-MS) [16,17] and gas chromatography. However, these methods are very specialized, expensive, and time-consuming. Therefore, new, very sensitive, specific, fast, and inexpensive alternative methods are still desired. 
MOFs, highly ordered porous crystalline containing metal ions and organic ligands, attracted attention for applications related to gas storage and separation [18-20], luminescent sensing [21-27], and catalysis [28-31] due to high surface area and suitable pore size. MOF structures are very diverse because of limitless combinations of their building blocks, cations (from main and transition groups), and ligands [32-34]. Thus, by varying cation/ligand, combination MOFs with various functionalities can be obtained. MOFs are considered excellent materials for supercapacitor and sensing applications.

Herein, a new Ni metal organic framework was synthesized and directly used as an electrode material for super capacitor and electrochemical sensing for sarcosine. The $\left[\mathrm{Ni}_{3}(\mathrm{BIPY})_{3}(\mathrm{BPDA})_{2}(\mathrm{HCOO})_{2}\left(\mathrm{H}_{2} \mathrm{O}\right)_{2}\right]_{n}\left(\mathbf{N i}-\mathbf{1} ; \mathrm{BIPY}=4,4^{\prime}\right.$-bipyridine; $\mathrm{BPDA}=2,2^{\prime}$ Biphenyldicarboxylate, CCDC number 1935262) exhibited a high specific capacitance, and long-term cycling stability. The Ni-1 exhibited good sensitivity and a wider range of linear response $1 \times 10^{-4} \mathrm{M}$ to $1 \times 10^{-3} \mathrm{M}$ for the determination of sarcosine. This is the first time that a new metal organic framework is served as supercapacitor electrode and sensor.

\section{Experimental Section}

\subsection{Materials and Methods}

Nickel nitrate hexahydrate was purchased from J\&K Chemical. 2,2'-Biphenyldicarboxylic and 4,4'-bipyridine were purchased from Jinan Henghua Technology company. All reagents used were commercially available and used without further purification. IR of $\left[\mathrm{Ni}_{3}(\mathrm{BIPY})_{3}(\mathrm{BPDC})_{2}(\mathrm{HCOO})_{2}\left(\mathrm{H}_{2} \mathrm{O}\right)_{2}\right]_{\mathrm{n}} \quad\left(\mathrm{Ni}-\mathbf{1} ; \mathrm{BIPY}=4,4^{\prime}\right.$-bipyridine; $\mathrm{BPDC}=2,2^{\prime}-$ Biphenyldicarboxylate) was recorded on Affinity-1 FT-IR spectrometer ranging from 200 to $4000 \mathrm{~cm}^{-1}$. Powder X-ray diffraction (PXRD) patterns were carried out through $\mathrm{Cu}$ Karadiation from $5-40^{\circ}$. Thermal gravimetric analysis (TG) was carried out by using aNetzsch STA $449 \mathrm{C}$ system with a heating rate of $5 \mathrm{~K} / \mathrm{min}$ under $\mathrm{N}_{2}$ protection.

\subsection{Synthesis of $\mathrm{Ni}-1$}

Firstly, 2,2'- Biphenyldicarboxylic Acid and 4,4'- bipyridine were dissolved in DMA to form $1 \mathrm{~mol} / \mathrm{L}$ DMA solution, and nickel nitrate hexahydrate was dissolved in water to form $1 \mathrm{~mol} / \mathrm{L}$ aqueous solution, The above solution $200 \mu \mathrm{L}: 300 \mu \mathrm{L}: 300 \mu \mathrm{L}$ and $8 \mathrm{~mL} \mathrm{H}_{2} \mathrm{O}$ was added to a $25 \mathrm{~mL}$ Teflon-lined stainless autoclave, sealed and heated at $160^{\circ} \mathrm{C}$ for $72 \mathrm{~h}$, then cooled to room temperature. The green block crystals of Ni-1 were obtained (yield: $75 \%$ based on $\mathrm{Ni}(\mathrm{II}))$.

\subsection{Single-Crystal Structure Determination}

Crystal of Ni-1 was collected from the mother liquor. Single-crystal data of Ni-1 were collected on a Rigaku Oxford CCD diffractometer equipped with graphite-monochromatic Mo-K $\alpha$ radiation $(\lambda=0.71073 \AA)$ at $293 \mathrm{~K}$. The structure was solved by direct methods, and refined by full-matrix least-square method with the OLEX-2 program package. The crystallographic data and refinements and the selected bond lengths and angles for Ni-1 are listed in Tables 1 and 2.

Table 1. Crystal data and structure refinement for Ni-1.

\begin{tabular}{ll}
\hline Compound & Ni-1 \\
\hline Chemical Formula & $\mathrm{C}_{60} \mathrm{H}_{54} \mathrm{~N}_{6} \mathrm{Ni}_{3} \mathrm{O}_{18}$ \\
Formula weight & 1323.16 \\
Crystal system & Monoclinic \\
Space group & $C 2$ \\
$a(\AA)$ & $22.501(2)$ \\
$b(\AA)$ & $11.2879(12)$ \\
$c(\AA)$ & $13.4015(12)$ \\
$\alpha\left(\left(^{\circ}\right)\right.$ & 90 \\
\hline
\end{tabular}


Table 1. Cont.

\begin{tabular}{ll}
\hline Compound & Ni-1 \\
\hline$\beta\left(^{\circ}\right)$ & $126.099(10)$ \\
$\gamma\left({ }^{\circ}\right)$ & 90 \\
$V\left(\AA^{3}\right)$ & $2750.3(5)$ \\
$Z$ & 2 \\
$D_{c}\left(\mathrm{~g} / \mathrm{cm}^{3}\right)$ & 1.598 \\
$\mu\left(\mathrm{mm}^{-1}\right)$ & 1.101 \\
$T(\mathrm{~K})$ & $293(2)$ \\
Wavelength $(\AA)$ & 0.71073 \\
$F(000)$ & 1368.0 \\
Crystal size $(\mathrm{mm})$ & $0.20 \times 0.19 \times 0.12$ \\
$\theta$ range $\left(^{\circ}\right)$ & 7.22 to 59.298 \\
Index ranges & $-28 \leq \mathrm{h} \leq 31$ \\
& $-15 \leq \mathrm{k} \leq 15$ \\
& $-18 \leq 1 \leq 16$ \\
Reflections collected & 11,900 \\
Independent reflections & $11,900\left[\mathrm{R}_{\text {int }}=0.0759, \mathrm{R}_{\text {sigma }}=0.1150\right]$ \\
Parameters & 396 \\
Goodness-of-fit on $F^{2}$ & 1.056 \\
$R_{1}$ indices $[I>2 \sigma(I)]$ & 0.0769 \\
$w R_{2}$ indices $[I>2 \sigma(I)]$ & 0.1609 \\
$R_{1}$ indices [all data] & 0.1005 \\
$w R_{2}$ indices $[$ all data] & 0.1772 \\
Peak and hole $\left(\mathrm{e} \AA^{-3}\right)$ & $1.37 /-0.95$ \\
\hline
\end{tabular}

Table 2. Selected Bond lengths [^] and Angles [deg] for Ni-1.

\begin{tabular}{|c|c|}
\hline Ni1- O1 = 2.029(7) & Ni2- $\mathrm{O} 3=2.078(8)$ \\
\hline Ni1- O7 = 2.048(6) & $\mathrm{Ni} 2-\mathrm{O}^{2}=2.078(8)$ \\
\hline Ni1- N2 = 2.090(12) & Ni2- N3 $=2.098(15)$ \\
\hline Ni1- O5 ${ }^{1}=2.091(6)$ & $\mathrm{Ni} 2-\mathrm{O}^{2}{ }^{2}=2.118(7)$ \\
\hline Ni1- N1 = 2.113(12) & $\mathrm{Ni2}-\mathrm{O} 2=2.118(7)$ \\
\hline Ni1- O5 = 2.120(6) & Ni2- N4 = 2.127(15) \\
\hline O1-Ni1-O7 98.1(3) & $\mathrm{O}-\mathrm{Ni2}-\mathrm{O} 3{ }^{2} \quad 176.6(5)$ \\
\hline O1-Ni1-N2 84.6(3) & O3-Ni2-N3 $88.3(3$ \\
\hline O7-Ni1-N2 87.3(4) & $\mathrm{O}^{2}{ }^{2}-\mathrm{Ni} 2-\mathrm{N} 3 \quad 88.3(3)$ \\
\hline O1-Ni1-O5 ${ }^{1}$ 93.2(3) & O3-Ni2-O2 ${ }^{2}$ 99.7(3) \\
\hline O7-Ni1-O5 ${ }^{1} \quad 168.4(3$ & $\mathrm{O}^{2}{ }^{2}-\mathrm{Ni} 2-\mathrm{O} 2^{2} \quad 80.4(3)$ \\
\hline N2-Ni1-O5 ${ }^{1} \quad 91.2(4)$ & $\mathrm{N} 3-\mathrm{Ni2}-\mathrm{O} 2^{2} \quad 91.0(2)$ \\
\hline O1-Ni1-N1 92.0(4) & O3-Ni2-O2 $80.4(3)$ \\
\hline O7-Ni1-N1 90.8(4) & $\mathrm{O}^{2}{ }^{2}-\mathrm{Ni} 2-\mathrm{O} 2 \quad 99.7(3)$ \\
\hline N2-Ni1-N1 175.9(3) & N3-Ni2-O2 91.0(2) \\
\hline O5 ${ }^{1-N i 1-N 1} \quad 91.3(4)$ & $\mathrm{O} 2^{2}-\mathrm{Ni} 2-\mathrm{O} 2 \quad 178.0(5)$ \\
\hline O1-Ni1-O5 168.3(3) & O3-Ni2-N4 91.7(3) \\
\hline O7-Ni1-O5 92.6(3) & $\mathrm{O}^{2}{ }^{2}-\mathrm{Ni} 2-\mathrm{N} 4 \quad 91.7(3)$ \\
\hline N2-Ni1-O5 91.1(4) & N3-Ni2-N4 180.0 \\
\hline O5 ${ }^{1}-\mathrm{Ni1}-\mathrm{O} 5 \quad 76.0(3)$ & $\mathrm{O} 2^{2}$-Ni2-N4 $89.0(2)$ \\
\hline N1-Ni1-O5 92.6(4) & O2-Ni2-N4 $89.0(2)$ \\
\hline
\end{tabular}

Symmetry transformations used to generate equivalent atoms: ${ }^{1} 1-X,+Y,-Z ;{ }^{2} 1-X,+Y, 1-Z$.

\subsection{Fabrication of Working Electrode}

$80 \%$ of Ni-1, $10 \%$ of acetylene black and $10 \%$ of PVDF were mixed in N-methyl pyrrolidone (NMP) until a homogeneous slurry was obtained, which was then applied to $\mathrm{Ni}$ foam and dried at $60^{\circ} \mathrm{C}$ in the air. Electrochemical sensing tests were performed using the glassy carbon electrode (GCE, model CHI104, $3 \mathrm{~mm}$ in diameter). Prior to the tests, it was polished with $0.05 \mu \mathrm{m}$ alumina, followed by ultrasonicated in $50 \% \mathrm{HNO}_{3}$, 
absolute ethanol and distilled water mixture for 30 at each step. Two milligrams of MOF was dispersed in $1 \mathrm{~mL}$ of DMF ultrasonically. Five microliters of this suspension was dropped onto the GCE surface to obtain a Ni-1 based working electrode (NHCPs-GCE).

\subsection{Electrochemical Measurements}

All the electrochemical measurements were conducted on an electrochemical workstation (CHI760E). In a three-electrode system, the Ni-1 was used as the working electrode, with Pt plate as the counter electrode, $\mathrm{Hg} / \mathrm{HgO}$ as the reference electrode, and $6 \mathrm{M} \mathrm{KOH}$ as the electrolyte, respectively.

\section{Results and Discussion}

\subsection{Structure Description}

The Compound Ni-1 shows two-dimensional structure and belongs to $C_{2}$ space group. The asymmetric unit contains one and a half nickel (II) centers, one bridging $\mathrm{BPDC}^{2-}$ group, one and a half BIPY, one formic acid group, and one water molecule. As shown in Figure 1, the $\mathrm{Ni}^{2+}$ are six-coordinated by four $\mathrm{O}$ atoms and two $\mathrm{N}$ atoms. In coordination mode of $\mathrm{Ni}(1), \mathrm{N} 1$, and $\mathrm{N} 2$ come from two bipyridine molecules, $\mathrm{O} 1$ is from biphenyl dicarboxylic acid molecules, $\mathrm{O} 6$ and $\mathrm{O} 6 \mathrm{~d}$ are from two formic acid molecules, and $\mathrm{O} 5$ is from water molecules. Formic acid comes from the decomposition of solvent molecules. In coordination mode of $\mathrm{Ni}(2), \mathrm{N} 3$ and $\mathrm{N} 4 \mathrm{a}$ are from two bipyridine molecules, $\mathrm{O} 2, \mathrm{O} 3, \mathrm{O} 2 \mathrm{c}$, and $\mathrm{O} 3 \mathrm{c}$ come from two $\mathrm{BPDC}^{2-}$ group (Figure 1). As a bridging ligand, two $\mathrm{N}$ atoms in pyridine participate in the coordination, and only three oxygen atoms of $\mathrm{BPDC}^{2-}$ group are involved in the coordination. It is interesting that in this structure, the conformation of the bipyridine molecule in which N1 is located is quite different from that of N3 (Figure 2). The bipyridine molecule in which N3 is located has a symmetry plane, and the two planes of $\mathrm{N} 3$ and $\mathrm{N} 4$ form a certain angle of $38.60(9)^{\circ}$, which is close to the normal bipyridine molecular structure, while the bipyridine molecule of N1is relatively deformed (without plane of symmetry), N1 and N2 the two planes rotate to the same plane through the $\delta$ bond between C17 and C18 (the angle is $14.89^{\circ}$ ). Although this conformation is not a stable conformation of the bipyridine molecule, the structure $\delta$-bond rotation precisely enhances the relationship between pyridine rings $\pi-\pi$ accumulation. In this two-dimensional structure, the bipyridine molecule where N1 resides forms a straight chain with Ni1 via a coordination bond. Similarly, the bipyridine molecule in which N2 resides forms another straight chain with $\mathrm{Ni} 2$ via a coordination bond. The $\mathrm{Ni}(1)$ chain and the other Ni1 chains are connected by $\mathrm{O} 6$ atom in two coordinated formic acid molecules. After connecting with Ni1 chain, Ni1 is coordinated with Ni2 chain via $\mathrm{O}$ atom of Biphenyldicarboxylic Acid Molecule. Finally, a two-dimensional layered structure is formed by O-coordination and $\pi-\pi$ stacking (Figure 3)

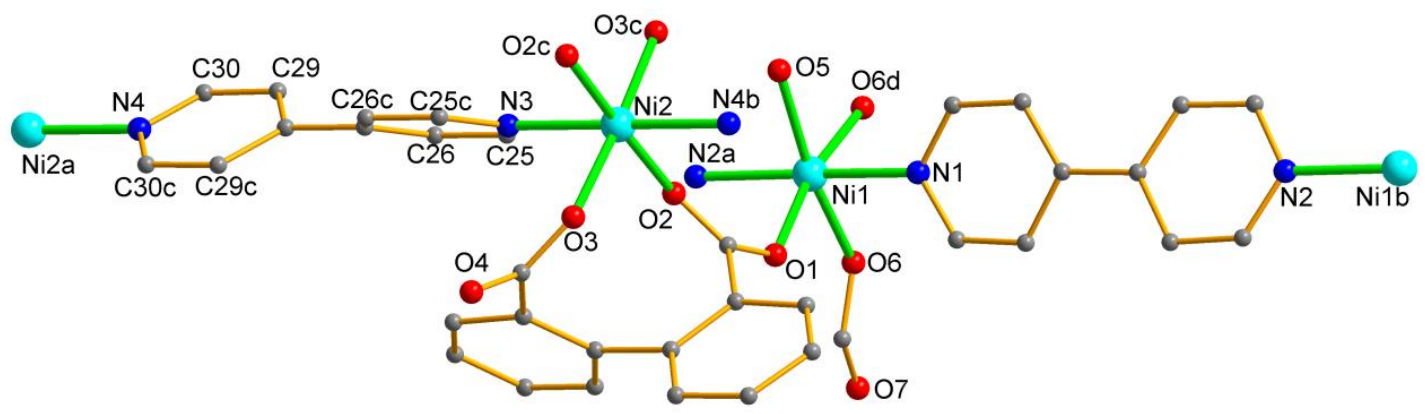

Figure 1. Coordination mode of Ni-1. Symmetric code: $a(x,-1+y, z), b(x, 1+y, z), c(1-x, y, 1-z), d(1-x, y,-z)$.

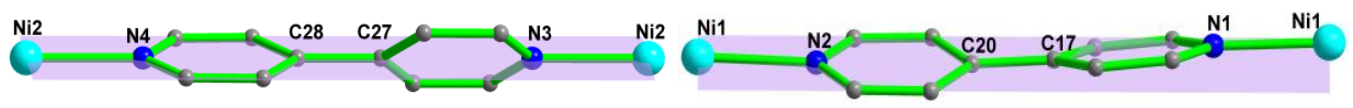

Figure 2. Conformations of two bipyridine molecules. 


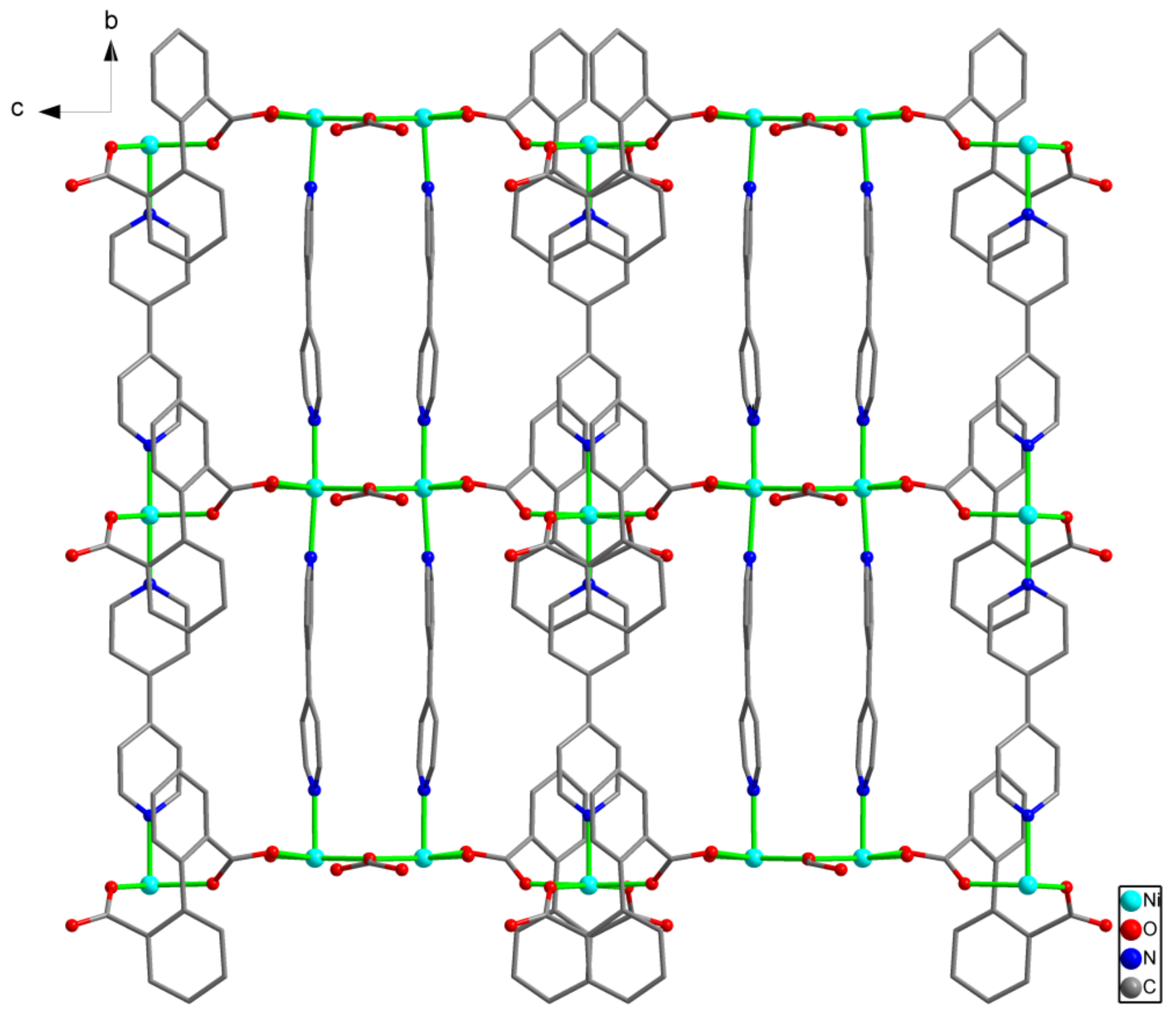

Figure 3. 2D structure in the a direction of Ni-1.

\subsection{Purity and Thermal Stability}

In order to explore the properties of Ni-1, the purity and thermal stability of the material were investigated. Figure 4a shows the PXRD patterns of the Ni-1, The PXRD patterns of Ni-1 showed the diffraction peaks corresponding to the simulated Ni-1 pattern. FT-IR spectrum of Ni-1 showed bands at 1610 and $1493 \mathrm{~cm}^{-1}$, which correspond to bending and stretching of $C=O$ (Figure $4 b$ ), while peaks at 1305 and $1542 \mathrm{~cm}^{-1}$ were ascribed to the pyridine bending. The Ni-1 thermal stability was analyzed by the thermogravimetric analysis (TGA) performed in the $50-800{ }^{\circ} \mathrm{C}$ range under $\mathrm{N}_{2}$ (see Figure $4 \mathrm{c}$ ). The first weight-loss stage occurred at $100-350{ }^{\circ} \mathrm{C}$ due to the loss of weakly bonded water and DMA solvent molecule. The second weight-loss step occurred at $350-400{ }^{\circ} \mathrm{C}$ due to the decomposition of the organic ligand in the MOF. 

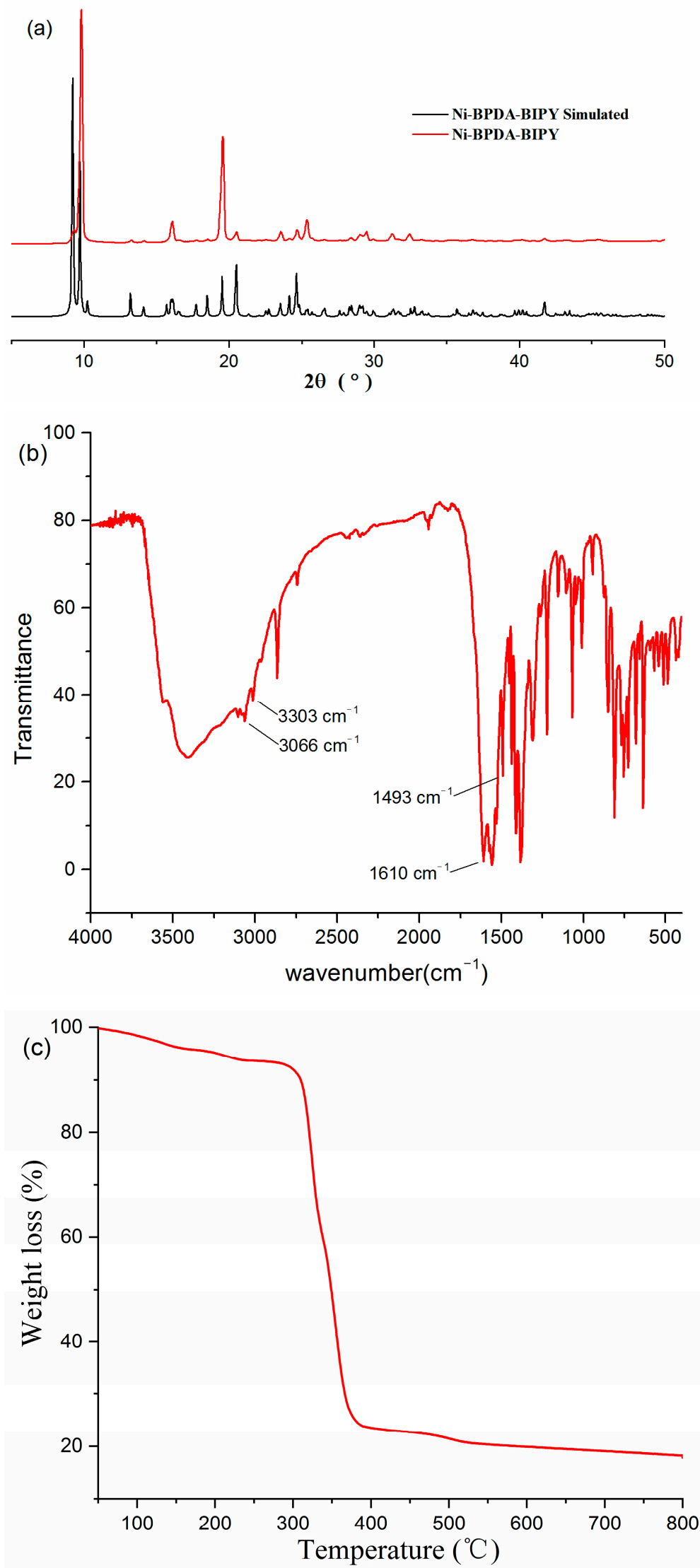

Figure 4. (a) PXRD patterns of simulated and the synthesized Ni-1; (b) FT-IR spectra of Ni-1; (c) Thermogravimetric analysis of Ni-1. 


\subsection{Investigation of Electrochemical Properties}

$\mathrm{CV}$ curves of the $\mathbf{N i - 1}$ supercapacitor electrode were recorded at $10-100 \mathrm{mV} / \mathrm{s}$ scan rates at $0-0.6 \mathrm{~V}$ showed faradaic redox peaks (see Figure $5 \mathrm{a}$ ), which is indicative of the Faradaic behavior. As the scan rate was increased, no changes in the redox peaks were detected, which indicates excellent rate capability of the Ni-1 based electrode. The GCD test showed that the specific capacitances of the Ni-1 based electrodes were equal to 667, $334,300,267$, and $240 \mathrm{~F} / \mathrm{g}$ at 1, 2, 5, 8, and $10 \mathrm{~A} / \mathrm{g}$ current densities, respectively (see Figure $5 b$ ). EIS tests showed straight curves in the low-frequency region (see Figure 5c), which indicates very low diffusion resistance and fast ion diffusion of electrolyte in the Ni-1 based electrode. Such excellent electrochemical properties are very beneficial for excellent capacitive performance. Analysis of the EIS curve in the high-frequency region revealed low resistance (Rs), judging by the small intercept of the arc with the real axis. Thus, the Ni-1 based electrode possessed low intrinsic and ionic resistances as well as excellent contact resistance with the current collector. The retention rate is up to $82 \%$ after 5000 cycles at a current density of $1 \mathrm{~A} / \mathrm{g}$, which indicates good cycling performance and stability. The capacitance in comparison with those reported ones is depicted in Table 3.
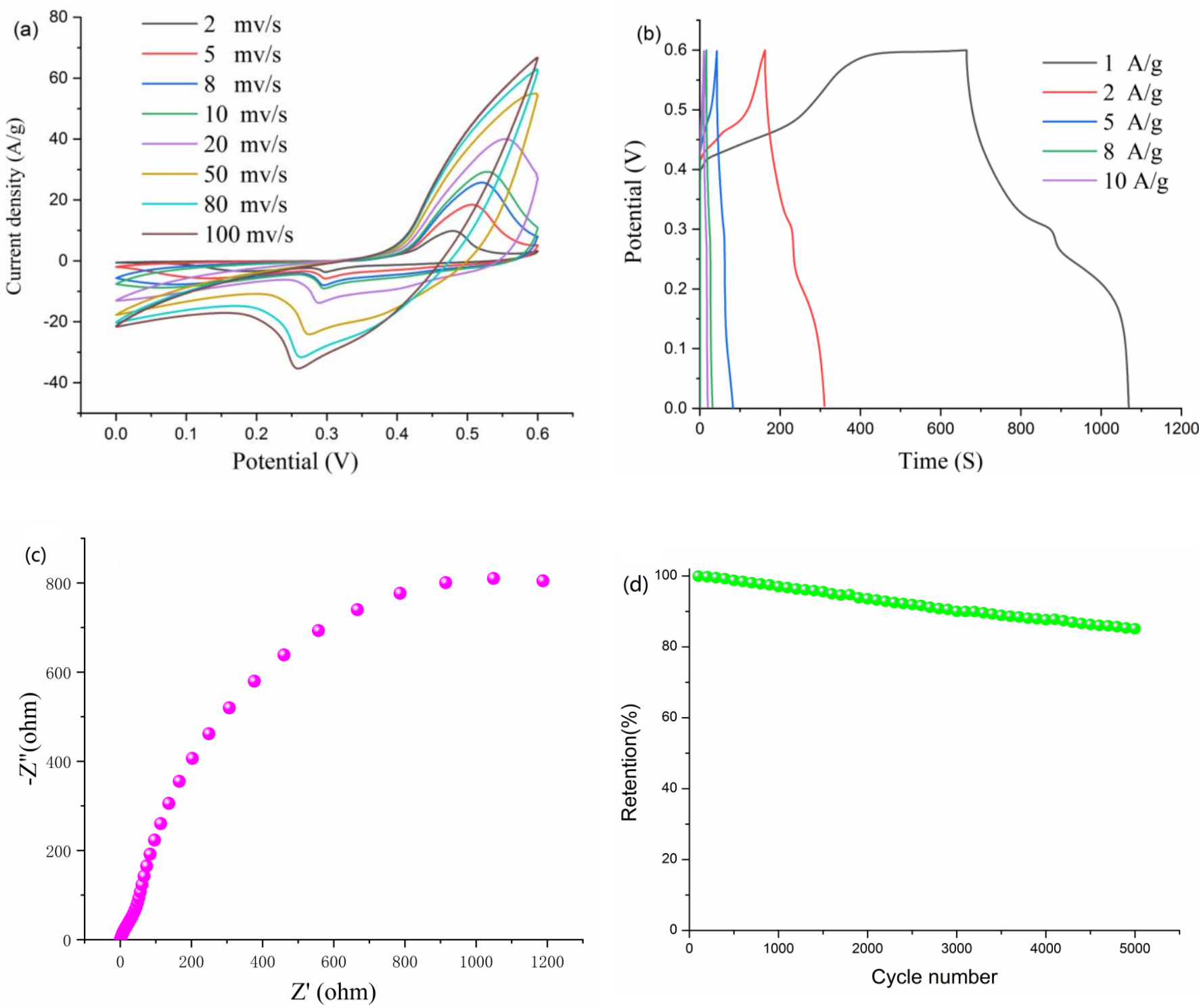

Figure 5. (a) CV curves at different scan rates from $2 \mathrm{mV} / \mathrm{s}$ to $100 \mathrm{mV} / \mathrm{s}$ and (b) GCD curves at different current densities from 1 to $10 \mathrm{~A} / \mathrm{g}$. (c) Electrochemical impedance spectra of Ni-1. (d) Cyclic stability of Ni-1 up to 5000 cycles. 
Table 3. Comparation of Ni-1 and other materials.

\begin{tabular}{ccc}
\hline Chemical Compound & Performance & Ref. \\
\hline$\left[\mathrm{Co}_{3}\left(\mu_{3}-\mathrm{OH}\right)(\mathrm{L})_{2}\left(\mathrm{H}_{2} \mathrm{O}\right)_{3}\right]^{-}$ & $300 \mathrm{~F} / \mathrm{g}$ & {$[35]$} \\
$\mathrm{Co}-\mathrm{MOF}$ & $206 \mathrm{~F} / \mathrm{g}$ & {$[36]$} \\
{$\left[\mathrm{Zn}_{3}(\mathrm{NIPA})_{3}(1,3-\mathrm{dpp})\left(\mathrm{H}_{2} \mathrm{O}\right)_{2} \cdot \mathrm{H}_{2} \mathrm{O}\right] \mathrm{n}$} & $22.8 \mathrm{~F} / \mathrm{g}$ & {$[37]$} \\
\hline
\end{tabular}

\subsection{Selectivity and Stability of the Sensor}

The selectivity of the Ni-1/GCE-based electrode was tested under the presence of $1.0 \mathrm{mM}$ species (Streptomycin, Erythromycin, Norfloxacin, Tetracycline, Tryptophan) with $0.1 \mathrm{M} \mathrm{KOH}$ as an electrolyte. The presence of the compounds did not affect the performance of our electrode (see Figure $6 \mathrm{~b}$ ), which indicates excellent anti-interference properties of our Ni-1/GCE.

Figure 6c exhibits the DPV curves of the Ni-1/GCE (recorded at $0.2-0.6 \mathrm{~V} / \mathrm{s}$ scan rate and $0.2-0.6 \mathrm{~V}$ range in $0.1 \mathrm{M} \mathrm{KOH}$ ) under the presence of $1 \times 10^{-4}-1 \times 10^{-3} \mathrm{M}$ of sarcosine. The peak current rose linearly (with the correlation coefficient $R^{2}=0.9981$, see Figure $4 \mathrm{c}$ ) as the sarcosine content in the solution was increased, which indicates excellent sensitivity of the electrode. This linear relationship could be expressed as I (A) $=0.95044 \times$ -1.4326 . The shelf life of the Ni-1 based GCE was examined by its response (measured every two days) during its storage at $2{ }^{\circ} \mathrm{C}$ for two weeks. Our sensor demonstrated the same current after 10 days of storage (see Figure 6e,f), which suggests its excellent storage stability and post-storage performance.
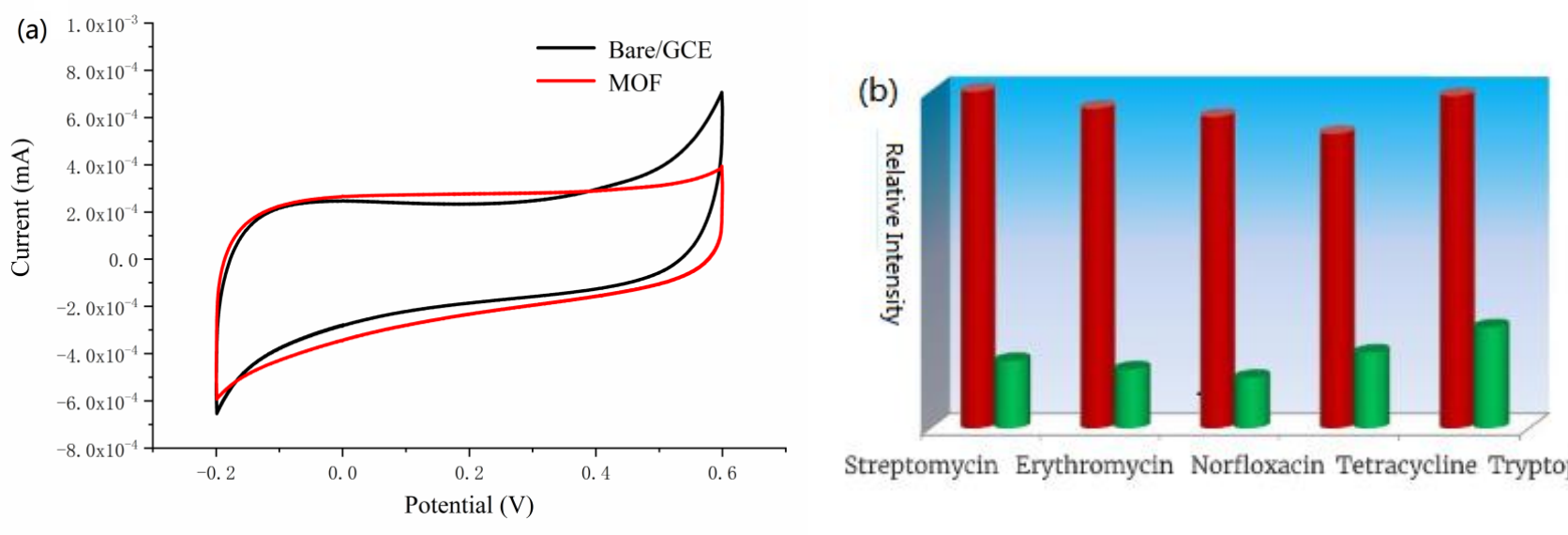

Streptomycin Erythromycin Norfloxacin Tetracycline Tryptophan

Figure 6. Cont. 

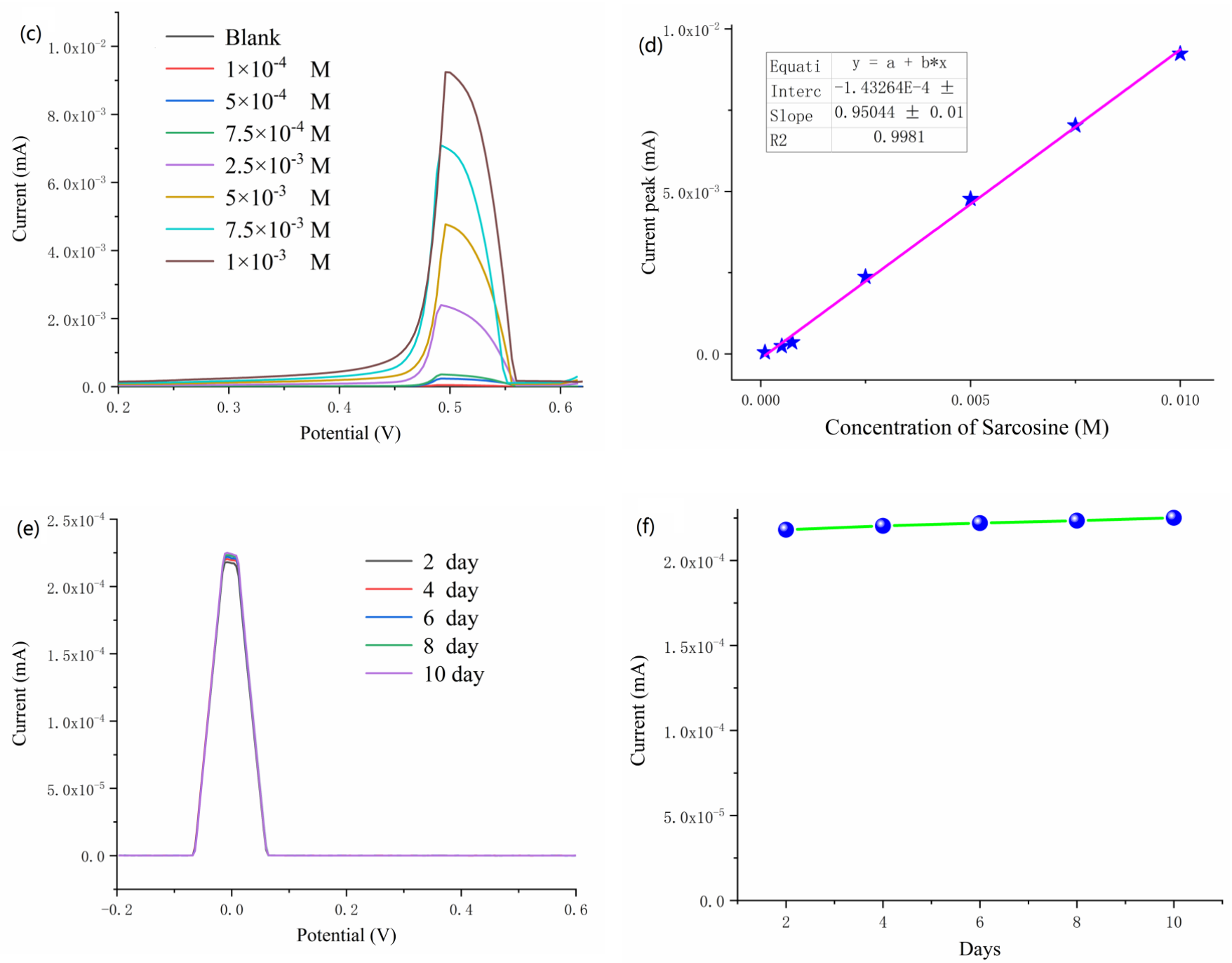

Figure 6. (a) CV curves of bare GCE and Ni-1/GCE (b) The ratios of current peak intensities of in KOH electrolyte solutions after the respective additions of different interferences with a coexisting concentration of $1.0 \mathrm{mM}$ sarcosine (c) DPV curves of the Ni-1/GCE with successive additions of sarcosine in $0.1 \mathrm{M} \mathrm{KOH}$, and (d) peak current versus sarcosine concentration plot showing a linear relationship (e,f) peak current of the electrode after two weeks.

\section{Conclusions}

We developed a novel $\mathrm{Ni}^{2+}$-containing metal-organic framework (Ni-MOF) material, which was then used as an active material for sarcosine sensing and for a high-performing supercapacitor (with excellent capacitance $667 \mathrm{~F} / \mathrm{g}$ at $1 \mathrm{~A} / \mathrm{g}$ and long-term cycling stability $82 \%$ after 5000 cycles). In fact, the sensor was very sensitive to sarcosine (with a low detection limit), and its response was linear relative to the increasing sarcosine contractions. Sarcosine was even detected when other interfering substances (such as Streptomycin, Erythromycin, Norfloxacin, Tetracycline, Tryptophan) were present. Our results strongly indicate that the Ni-MOFs are aspiring materials for next-generation supercapacitors and sensors.

Author Contributions: Conceptualization: S.L.; Methodology: S.L.; Writing一original draft: Y.W. (Yi Wang);Visualization: C.Z. (Chenyang Zhang); Validation: Y.W. (Yunying Wu); Formal analysis: B.Z.; Software: C.Z. (Chunjuan Zhou); Investigation: H.Y.; All authors have read and agreed to the published version of the manuscript. 
Funding: Financial support from Guangdong Province Department of Education Innovation Strong school funding (2018KTSCX136), Hanshan Normal University (XN201925).

Data Availability Statement: https:/ / ccdc.cam.ac.uk/ (accessed on 28 August 2021).

Acknowledgments: Thanks for the support of Guangdong Chaoshan Institute of higher education and technology.

Conflicts of Interest: The authors declare that they have no known competing financial interests.

\section{References}

1. Zheng, K.; Zeng, Y.X.; Liu, S.; Zeng, C.H.; Tong, Y.X.; Zheng, Z.K.; Zhu, T.S.; Lu, X.H. Valence and Surface Modulated Vanadium Oxide Nanowires as New High-Energy and Durable Negative Electrode for Flexible Asymmetric Supercapacitors. Energy Storage Mater. 2019, 22, 410-417. [CrossRef]

2. Li, J.; Xia, W.; Tang, J.; Tan, H.; Wang, J.; Kaneti, Y.V.; Bando, Y.; Wang, T.; He, J.; Yamauchi, Y. MOF nanoleaves as new sacrificial templates for the fabrication of nanoporous $\mathrm{Co}-\mathrm{Nx} / \mathrm{C}$ electrocatalysts for oxygen reduction. Nanoscale Horiz. 2019, 4, $1006-1013$. [CrossRef]

3. Young, C.; Kim, J.; Kaneti, Y.V.; Yamauchi, Y. One-Step Synthetic Strategy of Hybrid Materials from Bimetallic Metal-Organic Frameworks for Supercapacitor Applications. ACS Appl. Energy Mater. 2018, 1, 2007-2015.

4. Zhang, S.; Xi, W.; Yang, Q.; Kaneti, Y.V.; Xu, X.; Alshehri, S.M.; Ahamad, T.; Hossain, M.S.A.; Na, J.; Tang, J.; et al. Core-shell motif construction: Highly graphitic nitrogen-doped porous carbon electrocatalysts using MOF-derived carbon@COF heterostructures as sacrificial templates. Chem. Eng. J. 2020, 396, 125154. [CrossRef]

5. Vijayakumar, M.; Sankar, A.B.; Rohita, D.S.; Rao, T.N.; Karthik, M. Conversion of Biomass Waste into High Performance Supercapacitor Electrodes for Real-Time Supercapacitor Applications. ACS Sustain. Chem. Eng. 2019, 7, 17175-17185. [CrossRef]

6. Han, Y.; Lu, Y.Z.; Shen, S.H.; Zhong, Y.; Liu, S.; Xia, X.H.; Tong, Y.X.; Lu, X.H. Enhancing the Capacitive Storage Performance of Carbon Fiber Textile by Surface and Structural Modulation for Advanced Flexible Asymmetric Supercapacitors. Adv. Funct. Mater. 2019, 29, 1806329. [CrossRef]

7. Liu, T.; Li, C.Y.; Liu, H.C.; Zhang, S.; Yang, J.L.; Zhou, J.; Yu, J.L.; Ji, M.W.; Zhu, C.Z.; Xu, J. Tear resistant Tyvek/Ag/poly(3,4ethylenedioxythiophene): Polystyrene sulfonate (PEDOT:PSS)/carbon nanotubes electrodes for flexible high-performance supercapacitors. Chem. Eng. J. 2020, 2020, 127665. [CrossRef]

8. Soram, B.S.; Dai, J.Y.; Thangjam, I.S.; Kim, N.H.; Lee, J.H. One-step electrodeposited MoS ${ }_{2} @ N i-m e s h$ electrode for flexible and transparent asymmetric solid-state supercapacitors. J. Mater. Chem. A 2020, 8, 24040-24052. [CrossRef]

9. Liu, Y.L.; Yan, C.; Wang, G.G.; Li, F.; Shang, Y.; Zhang, H.Y.; Han, J.C.; Yang, H.Y. Self-templated formation of (NiCo) ${ }_{9} \mathrm{~S}_{8}$ yolkshelled spheres for high-performance hybrid supercapacitors. Nanoscale 2020, 12, 23497-23505. [CrossRef] [PubMed]

10. Zhang, X.L.; Wang, J.M.; Sui, Y.W.; Wei, F.X.; Qi, J.Q.; Meng, Q.K.; He, Y.Z.; Zhuang, D.D. Hierarchical Nickel-Cobalt Phosphide/Phosphate/Carbon Nanosheets for High-Performance Supercapacitors. ACS Appl. Nano Mater. 2020, 3, 11945-11954. [CrossRef]

11. Wang, Y.Z.; Ji, S.Y.; Xu, H.Y.; Zhao, W.; Xu, J.J.; Chen, H.Y. Bidirectional Electrochemiluminescence Color Switch: An Application in Detecting Multimarkers of Prostate Cancer. Anal. Chem. 2018, 90, 3570-3575. [CrossRef]

12. Mbage, B.; Li, Y.M.; Si, H.P.; Zhang, X.Y.; Li, Y.; Wang, X.H.; Salah, A.; Zhang, K.Z. Fabrication of folate functionalized polyoxometalate nanoparticle to simultaneously detect $\mathrm{H}_{2} \mathrm{O}_{2}$ and sarcosine in colorimetry. Sens. Actuators B 2020, $304,127429$. [CrossRef]

13. Yang, Q.G.; Li, N.; Li, Q.; Chen, S.Q.; Wang, H.L.; Yang, H.P. Amperometric sarcosine biosensor based on hollow magnetic $\mathrm{Pt}-\mathrm{Fe}_{3} \mathrm{O}_{4} @ \mathrm{C}$ nanospheres. Anal. Chim. Acta 2019, 1078, 161-167. [CrossRef]

14. Hu, J.; Wei, W.W.; Ke, S.M.; Zeng, X.R.; Lin, P. A novel and sensitive sarcosine biosensor based on organic electrochemical transistor. Electrochim. Acta 2019, 307, 100-106. [CrossRef]

15. Roy, A.; Chen, Y.P.; Qiu, J.T.T.; Maikap, S. Sarcosine Prostate Cancer Biomarker Detection by Controlling Oxygen inNiO Membrane on Vertical Silicon Nanowires in Electrolyte-Insulator-Nanowire Structure. Anal. Chem. 2020, 92, 8064-8071. [CrossRef] [PubMed]

16. Meyer, T.E.; Fox, S.D.; Issaq, H.J.; Xu, X.; Chu, L.W.; Veenstra, T.D.; Hsing, A.W. A Reproducible and High-Throughput HPLC/MS Method To Separate Sarcosine from $\alpha$ - and $\beta$-Alanine and To Quantify Sarcosine in Human Serum and Urine. Anal. Chem. 2011, 83, 5735-5740. [CrossRef] [PubMed]

17. Jiang, Y.Q.; Cheng, X.L.; Wang, C.; Ma, Y.F. Quantitative Determination of Sarcosine and Related Compounds in Urinary Samples by Liquid Chromatography with Tandem Mass Spectrometry. Anal. Chem. 2010, 82, 9022-9027. [CrossRef]

18. Yin, C.; Zhuang, Q.; Xiao, Q.; Wang, Y.; Xie, J. Electropolymerization of poly(methylene blue) on flower-like nickel-based MOFs used for ratiometric electrochemical sensing of total polyphenolic content in chrysanthemum tea. Anal. Methods 2021, 13, 1154-1163. [CrossRef]

19. Hu, R.; Zhang, X.; Chi, K.N.; Yang, T.; Yang, Y.H. Bifunctional MOFs-Based Ratiometric Electrochemical Sensor for Multiplex Heavy Metal Ions. ACS Appl. Mater. Interfaces 2020, 12, 30770-30778. [CrossRef] [PubMed] 
20. Gumilar, G.; Kaneti, Y.V.; Henzie, J.; Chatterjee, S.; Na, J.; Yuliarto, B.; Nugraha, N.; Patah, A.; Bhaumik, A.; Yamauchi, Y. General synthesis of hierarchical sheet/plate-like $\mathrm{M}-\mathrm{BDC}(\mathrm{M}=\mathrm{Cu}, \mathrm{Mn}, \mathrm{Ni}$, and $\mathrm{Zr})$ metal-organic frameworks for electrochemical non-enzymatic glucose sensing. Chem. Sci. 2020, 11, 3644-3655. [CrossRef]

21. Yang, L.F.; Qian, S.H.; Wang, X.B.; Cui, X.L.; Chen, B.L.; Xing, H.B. Energy-efficient separation alternatives: Metal-organic frameworks and membranes for hydrocarbon separation. Chem. Soc. Rev. 2020, 49, 5359-5406. [CrossRef]

22. Murray, L.J.; Dincă, M.; Long, J.R. Hydrogen storage in metal-organic frameworks. Chem. Soc. Rev. 2009, 38, 1294-1314. [CrossRef]

23. Mason, J.A.; Veenstra, M.; Long, J.R. Evaluating metal-organic frameworks for natural gas storage. Chem. Sci. $2014,5,32-51$. [CrossRef]

24. Lustig, W.P.; Mukherjee, S.; Rudd, N.D.; Desai, A.V.; Li, J.; Ghosh, S.K. Metal-organic frameworks: Functional luminescent and photonic materials for sensing applications. Chem. Soc. Rev. 2017, 46, 3242-3285. [CrossRef] [PubMed]

25. Chen, H.J.; Fan, P.; Tu, X.X.; Min, H.; Yu, X.Y.; Li, X.F.; Zeng, J.L.; Zhang, S.W.; Cheng, P. A Bifunctional Luminescent Metal-Organic Framework for the Sensing of Paraquat and Fe3+Ions in Water. Chem. Asian J. 2019, 14, 3611-3619. [CrossRef] [PubMed]

26. Zheng, K.; Liu, Z.Q.; Huang, Y.; Chen, F.; Zeng, C.H.; Zhong, S.L.; Ng, S.W. Highly luminescent Ln-MOFs based on 1,3adamantanediacetic acid as bifunctional sensor. Sens. Actuators B Chem. 2018, 257, 705-713. [CrossRef]

27. Wang, J.; Jiang, M.; Yan, L.; Peng, R.; Huang, M.J.; Guo, X.X.; Li, Y.; Wu, P.Y. Multifunctional LuminescentEu(III)-Based MetalOrganic Framework for Sensing Methanol and Detection and Adsorption of Fe(III) Ions in Aqueous Solution. Inorgan. Chem. 2016, 55, 12660-12668. [CrossRef] [PubMed]

28. Huang, N.; Drake, H.; Li, J.L.; Pang, J.D.; Wang, Y.; Yuan, S.; Wang, Q.; Cai, P.Y.; Qin, J.S.; Zhou, H.C. Flexible and Hierarchical Metal-Organic Framework Composites for High-Performance Catalysis. Angew. Chem. Int. Ed. 2018, 57, 8916-8920. [CrossRef] [PubMed]

29. Maeda, K.; Uemura, Y.; Chun, W.J.; Satter, S.S.; Nakajima, K.; Manaka, Y.; Motokura, K. Controllable Factors of Supported Ir Complex Catalysis for Aromatic C-H Borylation. ACS Catal. 2020, 10, 14552-14559. [CrossRef]

30. Karmakar, A.; Pombeiro, A.J.L. Recent advances in amide functionalized metal organic frameworks for heterogeneous catalytic applications. Coord. Chem. Rev. 2019, 395, 86-129. [CrossRef]

31. Fei, H.H.; Shin, J.W.; Meng, Y.S.; Adelhardt, M.; Sutter, J.; Meyer, K.; Cohen, S.M. Reusable Oxidation Catalysis Using MetalMonocatecholato Species in a Robust Metal-Organic Framework. J. Am. Chem. Soc. 2014, 136, 4965-4973. [CrossRef] [PubMed]

32. Ghasemzadeh, M.A.; Eshkevari, B.M.; Tavakoli, M.; Zamani, F. Metal-organic frameworks: Advanced tools for multicomponent reactions. Green Chem. 2020, 22, 7265-7300. [CrossRef]

33. Bao, Z.B.; Chang, G.G.; Xing, H.B.; Krishna, R.; Ren, Q.L.; Chen, B.L. Potential of microporous metal-organic frameworks for separation of hydrocarbon mixtures. Energy Environ. Sci. 2016, 9, 3612-3641. [CrossRef]

34. Ajdari, F.B.; Kowsari, E.; Shahrak, M.N.; Ehsani, A.; Kiaei, Z.; Torkzaban, H.; Ershadi, M.; Eshkalak, S.K.; Asl, V.H.; Chinnappan, A.; et al. A review on thefield patents and recent developments over the application of metal organic frameworks (MOFs) in supercapacitors. Coord. Chem. Rev. 2020, 422, 213441. [CrossRef]

35. Ghosh, S.; Maity, C.K.; Nayak, G.C.; Nayek, H.P. A Cobalt(II) Metal-organic Framework Featuring Supercapacitor Application. J. Solid State Chem. 2020, 282, 121093. [CrossRef]

36. Lee, D.Y.; Yoon, S.J.; Shrestha, N.K.; Lee, S.-H.; Ahn, H.; Han, S.-H. Unusual energy storage and charge retention in Co-based metal-organic-frameworks. Microporous Mesoporous Mater. 2012, 153, 163-165. [CrossRef]

37. He, H.; Wang, G.; Shen, B.; Wang, Y.; Lu, Z.; Guo, S.; Zhang, J.; Yang, L.; Jiang, Q.; Xiao, Z. Three isostructural Zn/Ni nitro-containing metal-organic frameworks for supercapacitor. J. Solid State Chem. 2020, 288, 121375. [CrossRef] 